multi-centre trial, co-ordinated by the York Group, designed to evaluate treatment methods for adolescent sex offenders.

\section{References}

Abel G. Becker, J., Mittelman, M., Cunningham-Rather, J. et al. (1987) Self reported sex crimes of non-incarcerated paraphiliacs Journal of Interpersonal Violence, 2, 3-25.

BECKER, J. \& KAPLAN, M. (1993) Cognitive behavioural treatment of the juvenile sex offender. In The Juventle Sex Offender (eds H. Barbaree, W. Marshall \& S. Hudson) pp. 264-277. New York: Gulldford Press
GENERAL REgister OfFice fOR SCOTLAND (1991) Census 1991. HMSO.

HoMe OFFice (1989) Criminal Statistics for England and Wales (1989). HMSO.

JOHNSON, T. \& BERRY, C. (1989) Children who molest. Journal of Interpersonal Violence, 4, 185-203.

WATKINS, B. \& BENTOVIM, A. (1992) Sexual abuse of male children and adolescents. Journal of Child Psychology and Psychiatry. 33, 197-248.

David Will, Consultant in Adolescent Psychiatry, Edinburgh Healthcare Trust, The Young People's Unit, The Royal Edinburgh Hospital, Tipperlinn Road, Edinburgh EH10 5HF

\title{
Child in-patient treatment and family relationships
}

\author{
Jonathan Green
}

\begin{abstract}
Residential child psychiatry units inevitably offer a form of temporary parenting to their patients. This paper explores various effects of this 'parenting' task on the treatment process theoff and on a unit's relationship with parents. The potent thercpeutic opportunities as well as potential unwanted effects dertving from this role are described. An awareness of the processes involved along with appropriate case management can maxlmise the benefits and minimise the unwanted effects of this factor within in-patient treatiment.
\end{abstract}

As with any residential environment for children, the in-patient child psychiatry unit has a number of basic legal responsibilities for care in loco parentis. Given our therapeutic task and the fact that so many of the problems we see involve problems in child-parent relationships, this 'parental' role of the ward is bound to become elaborated, and itself a factor in treatment. In addition, the creation of a ward treatment milieu inevitably involves various levels of parent-like activity from ward staff - although there has been debate throughout the history of in-patient units about how this should best be done. (Green 1992, 1993; Wardle, 1991; Hersov \& Bentovim, 1985).

While different therapeutic orientations may emphasise or minimise the unit's 'parental' function (for instance recent developments in the theory of child in-patient treatment towards 'minimal intervention' and the shorter stays (Harper, 1989; Nurcombe, 1989) will tend to minimise it), I believe that any in-patient unit which aims to do more than the briefest containment work will be faced with the need to address childrens' often deep attachment to a ward and the effect of this on families and a therapeutic relationship with parents.

Understandably, there is sometimes professional concern about in-patient treatment for children centring around just these issues, including the effect of separating children from their families; staff on in-patient units are often similarly preoccupied by their 'parental' role and the impact of admission on family life. On the other hand, residential treatment is usually undertaken within the context of very serious need, and has the potential for intensive and deep therapeutic work with families as well as children. I want to address these paradoxes in this paper. I outline a number of common stages in the development of the unit's relationship to families observed during admissions in my unit, suggesting the therapeutic potential as well as possible unwanted effects associated with them. I will also discuss steps in clinical management that may maximise the advantages and minimise potential disadvantageous effects of these dynamics.

\section{Stage 1: admission and engagement}

The moment of admission is a major event for both child and family. I do not think any amount 
of preadmission preparation can quite prepare for it. The child takes time to adjust to the new environment; the parents may hover anxiously, disengage with relief or engage well. The ward team will be preoccupied with making an accommodation with the child, assessment, and engaging the family.

At this point, I see the parent firstly as a 'consumer', having chosen and accepted the unit as temporary accommodation for their child, and then hopefully as a 'collaborator' in a therapeutic alliance with shared treatment objectives. It is later, in the next stage of work, that we may (depending on the nature of the case) wish to engage with them as 'patients', needing therapy in their own right, or within family work. Transitions between these different roles require negotiation and tact.

In this early phase professional attention is free-floating and staff discussions about the case can be wide-ranging, intuitive and exploratory (even through many of the individual assessments themselves will be structured and focused). Different members of the team will engage with different parts of the family or wider professional system, and this fact may lead to a mirroring in which the team reproduces some of the processes of family or system within itself. This mirroring contains information for the assessment but can also be a first challenge; to be able to tolerate and reflect on a certain amount of uncertainty and disagreement and use this as information rather than becoming spilt among ourselves.

Problems in this first engagement state can be various. In systemic terms admission can simply be a mistake, in effect colluding with a scapegoating within the family, or removing children from their main source of stability and continuity, say school. The parents may wish to hand over care without accepting a role as collaborator or patient themselves. The impact of admission and the frequent ambivalence of parents relating to it may be insufficiently explored and undermine real engagement from the start. In therapeutic terms we will often need to promote engagement by providing 'a secure base' for the child but also for parents, in order for the effective initial containment of distress and for treatment that the whole family needs to be made possible.

Reducing unwanted effects at this stage depends on good pre-admission assessment. consideration of the parent as 'consumer' with information and other pre-admission advice appropriately delivered, engagement with the parent as 'collaborator' by the agreement of shared treatment goals at a pre-admission meeting, and by giving an opportunity for the airing of parental ambivalence. Having a specific support group for parents is very helpful and in one unit inviting a parental representative onto the unit's management board has proved a successful measure (Dr Brian Jacobs, personal communication, 1993).

\section{Stage 2: treatment phase and parallel family work}

After the completion of the assessment and the formulation of a care plan there is often a marked shift where the unit 'takes on the case', and makes a therapeutic investment to treat child and family.

As part of this investment, everyday 'parental' type concerns inevitably arise - about feeding, safety, education, behaviour - and these place the nursing team in an interesting parallel position as caregiver to that of the parents. This fact can be very useful in our engagement with parents as adult collaborators in the service of the child.

At the same time there is an increasingly therapeutic engagement with the child, and also simultaneously (by another part of the team) with parents or the whole family or both. This 'parallel treatment' is an extraordinarily powerful phenomenon within in-patient treatment. The child is being 'parented' in an everyday sense by the ward and we are in a position to compare and share our experience as caregivers with the parents. Within the milieu of the ward the child is receiving 'parenting' from the ward team and involved in peer relationships and group work. The child is often also receiving specific individual therapy, and within this communicating his or her own subjective experience of life within his or her family. Simultaneously, the rest of the family itself is being seen and heard. In sum, this is an extraordinary opportunity for a powerful understanding and engagement with the case and the therapeutic task. It is at the core of the distinctive quality that is possible within in-patient treatment. The very intensity of this process can of course set up tensions between the unit and the child's parents. During relaxation and engagement with the ward in all its aspects, the child may begin to idealise it and denigrate home: this may be expressed during difficult weekends with the family (although just as often, in fact, behaviour at home dramatically improves). There can be a tendency for the child to 'split' these two sets of 'parents' and rivalry and envy can result. Unless great attention is paid to parental engagement at this point. the parents can come to feel de-skilled and demoralised or hostile.

This tension can also become mirrored within the staff team. Parts of the team closely involved and identified with the child may begin to reflect a hostility towards the parents, and the stage can 
be set for the destructive but not uncommon dynamic of 'parent blaming' within residential units (Penfold, 1991). Other team members working with the parents may, on the other hand, develop a more intergenerational perspective of the family's problems. Rival views of the case can thus gain ground based on involvement with different aspects of the family system. The potential for team splitting is here at its greatest, and a number of factors can for a time seem to promote a distancing of child from family. Individual growth of the child may sometimes seem to be only possible at the cost of destabilisation of the rest of the family: and these are issues that can have an ethical dimension (Green \& Stewart. 1987).

While these phenomena can in a way represent unwanted byproducts of in-patient treatment, they are also a consequence of the powerful engagement with child and family psychopathology that in-patient treatment makes possible (for instance some aspects of abuse may only be disclosable in this way). Levels of disclosure often become possible which remained invisible during out-patient treatment. This fact in itself can lead the way to powerful change and symptom relief. It is often the very fact of the emergence, recognition and working through of the tension at a team level and then with the family that can lead the way to a breakthrough in the treatment.

To the extent, however, that these phenomena are unwanted effects of the treatment, they can be minimised by attention to good and frequent communication with the parents and by a parental group programme. Parents can be prewarned that such developments commonly occur and can be worked through. The professional team needs to be functioning well and have the capacity to reflect on and resolve splitting when it occurs. There may also be implications for preadmission assessment and admission criteria. It may be that the intensity of such treatment is more than some families can contain or use therapeutically and pre-admission assessment should suggest that a more limited therapy be undertaken (or perhaps that substitute care rather than admission is more appropriate from the outset).

\section{Stage 3: ending and discharge}

The shift towards the ending phase is marked by the emergence of other themes. The ward's engagement with the child moves towards closure and ending, there is a feeling of resolution within the professional team, and whole family systemic work begins to take precedence. There are moves towards day patient status and increasing lengths of time at home. In our unit this shift is also marked, both practically and symbolically, by a discharge planning meeting during which the role of the parents as 'consumer' (in terms of plans for ongoing care) and as 'collaborator' (in terms of continuing progress after admission and generalising it to other environments) is emphasised. The disengagement of the child from the unit is marked in a number of ways with 'summing up' sessions and leaving parties.

As with any ending phase there are going to be feelings of loss and anxiety. There may be hyper-vigilance or protectiveness towards the child from the ward group and an escalation of symptoms from the child with anxious clinging or demands for alternative care. Families can swing between hope and despair about the future.

Problems at this time can also arise if the treatment phase has not been successfully negotiated. The family may not have made as much progress as the child, perhaps an underlying rejection may have become increasingly evident. The staff team may be concerned about child protection and safety issues, with a distressing feeling that the outside environment is not viable; and indeed for a minority of cases the admission may prove to be an important stepping stone to alternative parental provision. A tendency for the admission to 'drift' here can be an expression of the unit's own desire to offer substitute care for a distressed child, and needs to be watched for.

This discharge phase is often not easy. The use of structured and time limited admissions can, as in other brief therapies, help us to pace change and contain anxiety. A post admission period of regular brief contact can help to bridge the transition back to the referring service and home. Adequate local services and good communication with them are essential.

\section{Conclusion}

I have sketched out some of the therapeutic implications of the temporary psychological role of the child in-patient unit in loco parentis. My argument has been that although there are some risks associated with this role, it does constitute an important part of an in-patient unit's therapeutic effectiveness; in other words, like any other intense and powerful treatment, efficacy needs to balance against unwanted effects. I suggest that these unwanted effects can be minimised by appropriate management action. The key to good outcome is probably clear conceptualisation of the processes involved and good communication both within the unit team and between the team and the family in their various roles during an admission. 


\section{Acknowledgements}

I record great appreciation for the work of the in-patient team at Booth Hall, in collaboration with whom I have engaged these issues. Thanks to Dr Tracey Woods and Dr Ann Gilchrist and anonymous reviewers for their comments on earlier drafts of the paper.

\section{References}

GREEN, J.M. (1993) Inpatient treatment. In Managing Children with Psychiatric Problems (ed. M.E. Garralda.) London: BMJ Publications.

- (1992) Inpatient psychiatry units. Archives of Diseases in Childhood, 67, 1120-1123.

- \& STEWART, A. (1987) Ethical issues in child \& adolescent psychiatry. Journal of Medical Ethics, 13, 5-11.

HARPER, G. (1989) Focal inpatient treatment planning. Journal of American Academy of Child and Adolescent Psychiatry. 28, 38-37.
Hersov, L. \& Bentovim, A. (1985) Inpatient and dayhospital units. In Child \& Adolescent Psychiatry: modern approaches. (eds. M. Rutter and L. Hersov). Oxford: Blackwell Scientific Publications.

NURCOMBE, B. (1989) Goal directed treatment planning and the principles of brief hospitalisation. Journal of the American Academy of Child and Adolescent Psychitatry. 28, 26-30.

PEnFold, P.S. (1991) Mother Blaming on a Child Psychiatry Inpatient Unit. Presentation to the 9th Congress of the European Society for Child and Adolescent Psychiatry: London.

WARDLE, C.J. (1991) 20th century influences on the development in Britain of services for child and adolescent psychiatry. British Journal of Psychiatry, 169, 53-68.

Jonathan Green, Senior Lecturer and Honorary Consultant in Child and Adolescent Psychiatry; Consultant to the Inpatient Psychiatry Unit, Booth Hall Childrens Hospital, Manchester M9 7AA

\section{Psychiatry in Europe Directions and Developments \\ Edited by Tom Sensky, Cornelius Katona \& Stuart Montgomery \\ With the development of the European Union, psychiatrists in Britain are expanding their links with colleagues in continental Europe. This wide-ranging book discusses issues affecting modern psychiatric practice in Europe, such as legislative differences, collaborative projects and treatment priorities, as well as innovative techniques and research methods.

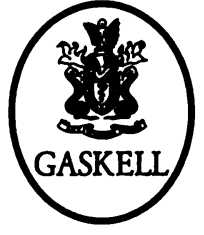 \\ $£ 10.00 \bullet 199 p p . \bullet 1994 \bullet$ ISBN 0902241710 \\ Available from the Publications Department, Royal College of Psychiatrists, 17 Belgrave Square, London SW1X 8PG (Tel. 0171-235 2351)}

